\title{
"FASCI ALL' ESTERO": APUNTES SOBRE LA COLONIA ITALIANA DE TACNA DURANTE EL RÉGIMEN DE MUSSOLINI (1930-1934)
}

\author{
"Beams abroad" notes on the italian colony in Tacna during the regime of \\ Mussolini (1930-1934)
}

\author{
Alfonso Vargas Murillo ${ }^{1}$
}

\begin{abstract}
RESUMEN
La política exterior del régimen de Mussolini, pasó de tomar poca importancia a las colonias italianas en el exterior, a entender su importancia geopolítica. Es asi que en el periodo que tratamos, durante el gobierno de Sánchez Cerro en el Perú, factores como la aceptación del fascismo por diversos intelectuales peruanos, la visión positiva de parte de la prensa nacional (y local), y la conformación de "fascios" en las colonias (el caso de Lima y Tacna) demuestran una fuerte influencia de la política italiana a nivel ideológico, no siendo asi a nivel de las relaciones diplomáticas entre ambos países.
\end{abstract}

Palabras Claves: Fascismo, colonia italiana, Perú, Tacna.

\section{ABSTRACT}

Foreign policy of Mussolini's regime went to take little importance to the Italian colonies abroad to understand their geopolitical importance. Thus in this period, during the government of Sánchez Cerro in Peru, factors such as the acceptance of fascism by various Peruvian intellectuals, the positive view by national (and local) press, and the formation of "Fascists" in the colonies (the case of Lima and Tacna) showed a strong influence of Italian politics at ideological level but not at the level of diplomatic relations between both countries.

Keywords: Fascism, Italian colony, Peru, Tacna.

\section{INTRODUCCIÓN}

En la década de 1930, en el contexto del ascenso al poder de Luis M. Sánchez Cerro tras propiciar un golpe de Estado al presidente Augusto B. Leguía, el nacimiento del partido ultra nacionalista (que posteriormente virara al fascismo, siendo el primero de esta clase y el más importante), la Unión Revoluciona- ria, la adhesión de historiadores, juristas y periodistas al fascismo (como se deja en evidencia en la antología "El Pensamiento Fascista" de José Ignacio López Soria) junto con la persecución hacia los comunistas y apristas que desencadenaría en hechos de violencia física y simbólica; la colonia italiana cumple un papel importante en la difusión, principalmente por medio de la prensa, de las

\footnotetext{
${ }^{1}$ Escuela de Derecho de la Universidad Privada de Tacna. Tacna-Peru.

Correo electrónico:avargasm95@gmail.com
} 
principales tesis del fascismo y de las obras de gobierno de "Il Duce" Benito Mussolini.

En el plano de las relaciones políticas internacionales, el régimen de Mussolini contó con representación, no solo a nivel diplomático, sino a nivel partidario. A pesar de que las relaciones diplomáticas con el régimen recién se fortalecerían al inicio de la Segunda Guerra Mundial, en los inicios de la década de 1930, los denominados "Fascios" - apéndices internacionales del Partido Nacional Fascista (PNF) - ya estaban consolidados en el Perú. Siendo el más importante, como señala José Ignacio López Soria en su obra "El Pensamiento Fascista", el Fascio de Lima, al mando de Toto Giuratto, que contaba con adherentes y apoyo considerable de la colonia italiana distribuida en todos los campos de la vida económica y social de la capital. En el plano local, como señala Giovanni Bonfiglio, se encontraba constituido un Fascio denominado Giovanni Berta, siendo el único en el interior del país.

Si bien el periodismo local no tuvo un rol directo con este Fascio, diarios como "La Nación" -bajo la dirección de Augusto Villa de la Tapia- o "La Verdad" sirvieron para la difusión de las ideas fascistas y propaganda de las obras del régimen de Mussolini en su proyecto de una "Nueva Italia".

Asimismo, la huella del fascismo está marcada en otras instituciones de la época, centrales en la vida de los emigrados italianos, como "La Casa de los Italianos" que fusionaba la Sociedad de Beneficencia Italiana, La Sociedad XX de Setiembre y el Circulo Italiano.

El presente trabajo pretende otorgar una visión general de la relación de la colonia italiana local con el régimen de Mussolini, en sus principales manifestaciones. Teniendo como fuente los diarios La Nación y La Verdad de los años 1930 a
1934, coyuntura en la que el fascismo gozaba de aceptación y adherencia por un sector del pueblo peruano, propiciado por el Partido Unión Revolucionara, fundado por Sánchez Cerro y posteriormente moldeado por Luis A. Flores hasta convertirlo en un partido de "camisas negras" al estilo italiano.

\section{COLONIA ITALIANA Y EL "FASCIO" ITALIANO}

Si bien las relaciones diplomáticas, como señala Flor de María Valdez Arroyo entre ambos países era bastante distante e indirecta, a pesar de la influencia a nivel ideológico que ejercía la política italiana-como se puede observar por medio de la prensa- ésta se fortalecerá recién al inicio de la Segunda Guerra Mundial, dándose "un lugar importante en materia de política exterior" (Valdez, 2004). Pero autores como Franco Savarino consideran que esto se trató solo de "un juego de ilusiones", a raíz de una lectura pragmática del fascismo de parte de América Latina, pero no obstante resulta de vital importancia la difusión del fascismo entre los emigrantes italianos y el papel que cumplieron como parte de la geopolítica italiana en esta región (Savarino, 2010).

Es así que las relaciones en este periodo, según Flor de María Valdez Arroyo, se manifiestan de cuatro formas, sobre las cuales la acogida que tuvo el fascismo en el Perú fue un factor importante:

"la simpatía que despierta el fascismo en sectores políticos y académicos [como se puede observar en los escritos de intelectuales de la época] [...] la intervención de Italia como miembro de la Sociedad de Naciones en el conflicto de Leticia, [...] llegada del fascismo al Perú, que conlleva a una estre- 
cha cooperación entre ambos Estados en el plano militar [...] y cuarto, en el plano multilateral, dada la posición del Perú respecto a la invasión italiana de Absinia (Etiopía) en 1935" (Valdez, 2004).

Curiosamente, el pensamiento fascista llega al Perú no por literatura italiana, sino por literatura española acerca de la Falange de José Antonio Primo de Rivera, movimiento inspirado en el fascismo italiano (Valdez, 2004), de donde serán desglosadas inicialmente las ideas esenciales de este movimiento, que se mostraba como vanguardia, frente a los partidos tradicionales.

En el plano nacional, como señala Ignacio López Soria especialmente en la capital, dentro de la colonia italiana había miembros del Fascio Italiano, los cuales se agruparon al mando de Toto Giurato y posteriormente por Massimo Gaetani, Donato Di Malio, Landi, Nosiglia, Radicati di Primeglio, Gino Salocchi y otros. Este Fascio contó tempranamente con órganos de expresión los cuales cumplían una función propagandística, como Italia Nuova, que dirigía Totto Giurato, el cual en un inicio se subtituló "Settimanale fascista". El propósito de este semanario era "sembrar la ideología fascista y en hacerla fructificar entre los miembros de la colonia italiana, [...] difundir los postulados básicos del fascismo, dar a conocer las posiciones de Mussolini y ganar la aprobación de italianos y peruanos con respecto a las campañas internacionales de Italia" (Lopez Soria, 1981).

También contó con el apoyo y presencia de diversas instituciones como el colegio Antonio Raimondi de Lima, la Compañía Italiana de Bomberos Garibaldi del Callao, Circolo Sportivo Italiano, en la Iglesia con los "servicios espirituales" del P. Ciro Simoni, así como con la contribución (especialmente en el sostén económico de sus publicaciones) del Banco Italiano, y de "empresarios italianos y diversas casas comerciales" (Lopez Soria, 1981).

\section{EL PROCESO DE "FASCISTIZACIÓN" DELAS COLONIAS}

Este proceso de "fascistizacion" de las colonias italianas se inicia en los años 20. Como señala Rubén Domínguez Méndez, en esa década, el fascismo intentó agrupar a todas las comunidades italianas en torno a la nueva ideología. "Una ambición que demostraba la importancia dada a los movimientos migratorios en la táctica de penetración cultural y económica en los países receptores" (Dominguez, 2012).

Asimismo, señala que para poder ejercer control sobre los colonos, el fascismo se valió, principalmente, de tres mecanismos: "el fascio local, el representante diplomático o consular y la denominada Casa d'Italia. Mediante éstos debían combinarse las actividades propagandísticas con las culturales y de ocio" (Dominguez, 2012). Más adelante podremos observar la importancia que ejercía cada uno, especialmente el "fascio" local y la "Casa degli Italiani"

Por tanto, se puede afirmar que, la emigración de los italianos fue utilizada por el gobierno de Mussolini, como medio de influencia geopolítica en el extranjero, y en este sentido se emprendió un programa que tenía como fin "conquistar la hegemonía política en las comunidades italianas y controlar las asociaciones asistenciales, sociales y culturales existentes, arrogándose el monopolio de la representación de la italianidad" (Gonzales Calleja, 1994).

Para Emilio Gentile "el proceso de fascistización se operó partiendo de la pretendida identidad entre italianidad y 
fascismo, y del papel asumido por el PNF como único, auténtico y legítimo intérprete del alma y la voluntad de la nación" (Gonzales Calleja, 1994). Franco Savarino afirma que factores como la gran influencia que ejercía Europa y la presencia de millones de emigrantes europeos, son elementos a favor que tenía el fascismo en América Latina, lo cual repercutió necesariamente en la sociedad peruana de aquella época; esto se vio reforzado por la popularidad de las ideas fascistas de carácter universal, en este sentido "Mussolini creía que el fascismo era universal en su espíritu e italiano en sus instituciones particulares, por lo tanto consideraba vital controlar, defender y promover la italianidad" (Savarino, 2010). En ese contexto, se empiezan a "fascistizar" las relaciones diplomáticas, colocando a las colonias bajo las órdenes del Ministerio de Relaciones Exteriores, de este modo entre 1928 y 1929 se crean " 70 nuevos consulados, se nombraron 120 cónsules fascistas y se dictó un nuevo estatuto para los fascios del exterior" (Grillo, 2006).

Para entender cómo el fascismo influyó en la sociedad peruana por medio de su política exterior, es necesario primero repasar la visión que tenía Italia de América Latina en aquel momento. Según Savarino (2010), para Italia, era una región:

1. Perteneciente a la civilización occidental en su variante "latina" pero periférica y dependiente de Europa.

2. Aun subdesarrollada, económica y culturalmente.

3. Caóticamente, heterogénea, hibrida en el aspecto antropológico-racial, con al presencia de elementos humanos "menos desarrollados" o "decaídos" (negros e indios).

4. Poco poblada y meta natural de la emigración europea.

5. Con estados débiles, poco definidos en términos políticos e institucionales, y en busca de inspiración externa.

6. Bajo la amenaza de una hegemonía angloamericana y asiática".

Una de las estrategias utilizadas para influir en este espacio, se basaba en la idea de "latinidad", se la presentó como parte constitutiva de la identidad peruana; así, en el plano nacional, se buscaba justificar la relación de los países latinoamericanos con Italia, no solo por cuestiones geoestratégicas, sino culturales, en cuanto se mostraba a Italia como la madre o la "abuela" -como afirmaba Riva Agüero- de Latinoamérica. "De lo que se trataba, en realidad, era de presentar el fascismo no sólo como fruto originario de lo latino sino como componente esencial de nuestro ser histórico" (Lopez Soria, 1981).

\section{COLONIA ITALIANA DE TACNA: UNA APROXIMACIÓN HISTÓRICA}

Giovanni Bonfiglio señala que el origen de los primeros italianos en Tacna se remonta a la colonia, pues era un nexo importante entre Bolivia y Arica para el desarrollo de sus actividades comerciales y aumentó en la segunda mitad del siglo XIX, a raíz de la construcción del ferrocarril Tacna-Arica, entre 1851 y 1854 , lo cual "aumentó el tráfico comercial en la zona, que se convirtió en un fuerte polo de atracción para los inmigrantes" (Bonfiglio, 1999).

En 1860, al menos treinta comerciantes italianos estaban operando Tacna, quienes contaban con uno o más empleados. A mediados de los años 60 , se encontraban en Tacna, entre 160 a 200 italianos. Hacia 1879, como, a raíz de las denuncias hechas por colonos italianos, producto de los saqueos producto de la guerra con Chile, se puede observar que la mayoría de italianos provenían de 
Liguria, así como en menor medida de Piamonte, Toscana, Lombardía, Basilicata y Campania (Bonfiglio, 1999).

Dicho autor señala que, como consecuencia de la Guerra del Pacífico, la ocupación de Tacna "produce una disminución repentina de actividades comerciales; muchos residentes italianos en la zona sufrieron grandes pérdidas como consecuencia de los saqueos y el bombardeo de ciudades y puertos" (Bonfiglio, 1999). A pesar de ello, luego de los sucesos de 1879, como señala Alfonso Díaz Aguada y Elías Pizarro Pizarro, se da un cambio en el panorama comercial con respecto a la hegemonía que ejercían las colonias inglesa, francesa y española. Un caso ejemplar es el del Banco de Tacna, fundado en 1872 y conformado hasta entonces por accionistas principalmente ingleses, franceses y alemanes, los cuales retiran sus acciones. A la llegada de los italianos, estos ocupan lugares entre los accionistas e incluso directivos (Diaz \& Pizarro, 2004).

En el mismo sentido, Oscar Panty Neyra, señala que "la guerra con Chile truncó el desarrollo del grupo burgués compuesto por ingleses, pero favoreció el grupo de origen italiano" (Choque, 1988). Así podemos encontrar la causa de la inmigración posterior a la Guerra del Pacífico al auge económico de la colonia italiana asentada, pues con la ocupación chilena, "al no contar con la presencia de otros capitales de importancia los transformó en el nuevo centro hegemónico de la actividad comercial de la región de Tacna" (Diaz \& Pizarro, 2004). En aquel periodo, dicha comunidad constituía un núcleo compacto, a dicho de Giovanni Bonfiglio, "probablemente la comunidad étnica italiana más unida del Perú" después de la de Lima, esto debido a la presencia de importantes instituciones al finalizar el siglo XIX, como la "Società Italiana di Beneficenza" y la "Società di Mutuo Soccorso XX Settembre" (Bonfiglio, 1999).

A inicios del siglo XX, en 1907, la "Società Italiana di Beneficenza" compra un terreno en el cementerio donde se construiría un mausoleo para los italianos muertos, iniciativa sin precedentes en la historia de la comunidad italiana en el país. En 1908 se funda la compañía Italia, la cual en el año 1930 donó todo a la unidad peruana de bomberos Tacna $\mathrm{N}^{\circ} 1$. (Bonfiglio, 1999). A pesar de quebrar el Banco de Tacna en 1921, la colonia italiana mantiene su hegemonía comercial, principalmente porque desde 1920 se produce una "fuerte transferencia inmobiliaria" esto producto de la inestabilidad de residencia de peruanos y extranjeros entre 1925 y 1928. "Fueron precisamente estos años de incertidumbre política, de los que la colonia italiana, a través de la voraz especulación inmobiliaria, supo capitalizar, lucrándose fácilmente" (Diaz \& Pizarro, 2004). Desde entonces y con el transcurso de los años, los italianos comenzaron a establecer una serie de negocios (desde pequeños negocios como pulperías, restaurantes, menestras, baratillos hasta sociedades que llegaron a dominar la actividad comercial local). Es necesario señalar que también tenían presencia en la administración pública, principalmente en el sector educación y salud (Diaz \& Pizarro, 2004).

En este sentido, Alfonso Diaz Aguad y Elías Pizarro Pizarro, afirman que la capacidad de organización y la facilidad para negociar a la par que dio un impulso a la economía de la ciudad, significó cierta innovación en la actividad comercial producto de las ideas traídas de Europa, de este modo a partir de la proliferación de negocios de diversa envergadura y la astucia para aprovechar los momentos claves, fueron factores que permitieron mantener un lugar 
central en la vida económica de la localidad Diaz \& Pizarro, 2004).

Hacia 1926, según el Informe Plebiscitario de Emilio Valverde, había 50 empresas en Tacna, de las cuales 25 eran italianas con $80 \%$ del capital, esto debido a que "los italianos se encumbraron con el comercio, hipotecas, arrendamientos, préstamos de dinero, custodia de bienes y representaciones de quienes emigraron por la guerra y las persecuciones durante la ocupación chilena" (Panty, 2001). Tras la reincorporación de Tacna al Perú, la comunidad empresarial italiana se vio "perturbada" producto de la crisis que golpeó a la banca nacional que reemplazó a la banca chilena y el reordenamiento político-administrativo, que no llegó a consolidarse en un inicio, lo cual dificultó la reinserción de Tacna a la vida económica del país (Panty, 2001). Hasta el año 1931, la colonia italiana estaba agrupada alrededor de tres asociaciones la Sociedad de Beneficencia Italiana, la Sociedad XX de Setiembre y el Circulo Italiano, las cuales en setiembre del mismo año, se fusionarían en la "Casa degli Italiani", asociación que englobaría todas las actividades que anteriormente se desarrollaban dispersas o independientemente. Entidades que buscarían recuperar el lugar en la vida económica de la localidad antes de la reincorporación. Y en 1932 se crea el "Giardino D'Infanzia Italiano", importante institución educativa que actualmente se llama Colegio Santa Ana, y que según Giovanni Bonfiglio, fue "la única en una ciudad del interior del país" (Bonfiglio, 1999). En 1935, el grupo de italianos era el más numeroso después del chileno, como se observa en el "Censo de Tacna, Calana y Pachia", con 160 habitantes, de una población de 10720 habitantes (Bonfiglio, 1999).

\section{"FASCI ALL'ESTERO" Y EL "FASCIO DETACNA"}

El optimismo y las expectativas que generaron el discurso del fascismo y su mensaje de renovación nacional en los italianos emigrados "llevó a la creación imitativa en diversos Estados de los fasci italianos, de manera espontánea y desordenada entre 1920 y 1922, principalmente por la acción de antiguos combatientes en la Gran Guerra" (Dominguez, 2012). Los fasci se crean como extensión del PNF en el exterior, como señala Emilio Gentile, con tres objetivos: el control ideológico, manifestado en la conversión de los emigrados al fascismo y el control de sus principales asociaciones (culturales, asistenciales, deportivas) y el de propaganda, que consistía en "activar un canal de propaganda económica y política favorable a la Italia fascista entre la opinión pública extranjera" (Dominguez. 2012). Es decir el "fascio" era una organización que tenía una labor de control político-ideológico, sirviendo de propaganda del régimen y producto de la asimilación de las asociaciones, se planteó defender con mayor eficacia los intereses del gobierno italiano en ultramar (sobre todo evitando la desnacionalización de los italianos). Así mismo este tipo de organizaciones, servía de contención al avance del internacionalismo socialista y su presencia en las colonias italianas.

A raíz de la primera aparición del "Fascio italiano di combatimento" en los Estados Unidos, el "Fascio de Nueva York", en 1921, Mussolini manifiesta en el Popolo d'Italia "el primer programa de los "Fasciall'Estero", las directrices eran:

"suscitar, conservar, exaltar la italianidad entre los millones de italianos dispersos por el mundo; conducirles a vivir más intensamente la vida de la metrópoli; 
estrechar, intensificar las relaciones -de cualquier género- entre las colonias y la madre patria; establecer auténticos consulados fascistas para la penetración legal y extralegal de todos los italianos" (Gonzales Calleja, 1994).

La expansión global del fenómeno fascista institucionalizado se aprecia en las siguientes cifras sobre los Fasci all'Estero:

"en 1928 sumaban 587 sedes, y censaban a 124870 adheridos. A mitad de 1929 se constataba la existencia de 583 fascios, de los cuales 289 estaban ubicados en Europa, 210 en América, 49 en África, 28 en Asia y 7 en Australia y Nueva Zelanda, con 101.500 inscritos, a los que se unían 23270 adherentes a las organizaciones juveniles. A fines de 1930, las cifras crecieron a 630 fascios con cerca de 140000 inscritos, de los cuales 20000 eran mujeres y 45000 jóvenes" (Gonzales Calleja, 1994).

El 24 de enero de 1928, se dicta el nuevo estatuto para los Fasci del exterior el cual establecía que esas organizaciones, buscando evitar conflictos en su lugar de residencia "elegían la obediencia al duce, pero debían acatar la ley del país que los hospedaba" (Grillo, 2006).

En un inicio, el control de tales organizaciones generó muchos problemas, como señala Caroline Pane, principalmente por los desacuerdos existentes entre el Ministerio de Relaciones Exteriores Italiano y la Secretaría General del Partido, supremos representantes del régimen en cuestiones de emigración, generando una dicotomía EstadoPartido, que fue resuelta con el nombramiento de Piero Parini como cabeza de los Fasci all'estero y del DGIE (Dirección General Italianos en el extranjero), órgano del Ministerio de Relaciones Exteriores, quien comenzó un reordenamiento de los Fasci, limitando su autonomía, como, por ejemplo, el no poder elegir libremente a sus líderes locales, sino designándolos por decisión del secretario general, buscando disminuir las tensiones entre los líderes de los Fasci y los cónsules locales. A inicios de los años 30 , fueron asimiladas en su totalidad por el Ministerio de Relaciones Exteriores y luego fueron encabezados por los cónsules y embajadores (Pane, 2012).

En el caso peruano, como señaláramos anteriormente, el Fascio en la capital estaba presidido inicialmente por Toto Giurato. En el caso de Tacna, la cantidad de inmigrantes y la cohesión existente en esta comunidad jugó un rol importante en el establecimiento de este tipo de organizaciones, como señala Giovanni Bonfiglio, "fue la única ciudad del interior donde funcionó de modo estable una sección del partido fascista, fundada en 1922, y llevó el nombre de Giovanni Berta"(Bonfiglio, 1999), quien fue un joven fascista italiano que fue apuñalado por un comunista y arrojado a un río (Vivarelli, 2012). Al año 1931 el "Fascio de Tacna" tenía como secretario a Máximo Castagnola (o Mássimo Castagnola) como evidencia el diario La Nación. La función de defensa del régimen de Mussolini por parte del Fascio local se observa en la réplica al artículo de Donato Gonzales R. (secretario de organización de la primera junta directiva del Sindicato de Empleados de Comercio, Banca e Industria de Tacna (Panty, 2001), socialista e indigenista (Ferreira de Cassone, 2008), quien usa duros calificativos para el "Duce" y su gobierno, como "el más cínico de los renegados [...] el engendrador de una de las más funestas tiranías reaccionarias 
de los tiempos actuales" (La Nación, 18 de setiembre de 1931, pág.4) que hace el Máximo Castagnola, quien firma como "Secretario del Fascio de Tacna".

"Los conceptos que este señor tiene formados del fascismo son completamente falsos pues ignora que este es resultado de la evolución del pensamiento del pueblo italiano "perfeccionado" a través de una historia que puede asegurarse la más grande del mundo $[\ldots]$ Como italiano que soy y afiliado al partido fascista, para satisfacción mía, de mis connacionales y de mi patria, no he podido dejar pasar por alto el discrepante artículo del señor González y me permito sugerirle que para sus próximos escritos use más tino y más prudencia. [...]" (La Nación N³11, 19 de setiembre de1931, pág.2)

En síntesis, los fascios locales servirían como "centinelas", controlando que no se vierta en la prensa opinión distinta que la oficial, proveniente de Italia, teniendo los colonos la autoridad para desacreditar cualquier información vertida por los medios locales o nacionales, que consideren inadecuada.

\section{LA "CASADEGLIITALIANI"}

Hacia 1928, empieza una nueva etapa para las organizaciones de italianos en el extranjero, con el doble nombramiento de Parini, como señala Caroline Pane, se dejó de exportar directamente "squadrismo" o ideales, moderándose el discurso enfocándose en luchar contra las desnacionalizaciones por medio de diversas actividades sociales reservadas solo para los emigrados, así surge una nueva estructura política "La Casa de los Italianos"o "Casa del Italiano", las cua- les estaban dirigidos por los secretarios del "Fascio" bajo la supervisión de los cónsules. (Pane, 2012). La citada autora, las describe de la siguiente forma:

"una Casa de Italia es un edificio [...] de propiedad o alquilado por el Estado fascista en el extranjero, que comprende la sede del fascio y autoridad consular, a la que se pueden anexar varias organizaciones del partido y asociaciones italianas. Apareció a finales de los años veinte como una herramienta para aumentar las fasci en el extranjero, las casas fueron desarrolladas en los años treinta con su regularización por la DGIE ("Dirección General de Italianos en el Extranjero): constituyéndose en las ciudades donde se encontraban como el único centro de la "italianidad", borrando cualquier otra representación oficial de carácter no-fascista." (Pane, 2012).

Estas casas cumplían una doble función con relación a la colonia: la primera sería "agruparlos bajo el banderín de la Casa, en torno a las organizaciones del partido, con el fin de mantenerlos alejados de la desnaturalización o cualquier pérdida de la identidad italiana, que era fascista" (Pane, 2012). La segunda fue servir como representación diplomática y en este sentido "ofreció a las autoridades extranjeras un seguro de orden público, cancelando la política "squadrista" de los primero fascistas y mostrando una cara más tranquila y moderada de la Italia fascista" (Pane, 2012).

Como señala Rubén Domínguez Méndez, y permitiéndonos hacer una analogía con la Casa Degli Italiani de Barcelona, el propósito de tomar el control de estas instituciones por parte del régimen de Mussolini, es ocupar los 
espacios de la tradición asociativa italiana y así crear un patronato que dirigiera toda la actividad asociativa autorizada y promovida por el gobierno de Mussolini. En este sentido, esta institución representaba el intento de conseguir el "reagrupamiento de todas las actividades coloniales italianas: Consulado, Cammera di Commercio, escuelas, asociaciones, etc." (Dominguez, 2012).

En el diario La Nación del 8 de setiembre, se publica una nota sobre el "Agasajo al canciller Cav. Sr. Casardi" con motivo de su visita a la localidad y cuando, según la nota periodística, se acordó la constitución de la "Casa degli Italiani", eligiendo como primer presidente a Lorenzo Tarabotto, el diario reseña:

"[...] Lorenzo Tarabotto que ocupó la Presidencia, tuvo felices palabras de patriótico recuerdo al amado Monarca, al grande Benito Mussolini que ha logrado la grandeza de la Nueva Italiana y concluyó su improvisación con esta bella frase: Es ella que se encausara hacia la altísima cumbre de su esplendente destino [...]

Cerró la manifestación el presidente de la sociedad recientemente constituida... que hizo recuerdo de la obra realizada por nuestro grande DUCE que por su obra hoy día Italia ocupa un rango preponderante en el consorcio de las naciones de Europa. Hizo un llamado hacia el soberano, al gran artífice de la futura Italia imperial [...] (La Nación, 8 de setiembre de 1931, pág. 4)

El regente consular, Julio César Raffo, quien también hizo uso de la palabra, fue nombrado Caballero de la Corona de Italia por el Gobierno de Mussolini. Quien lo sucedería al año siguiente sería Humberto Bollo, quien, como señala el diario La Verdad, formó parte del grupo de italianos que regresaron a servir a su patria en la Primera Guerra Mundial (La Verdad, 22 de agosto de 1933, pág.1).

Sin embargo, respecto a la creación de la "Casa degli Italiani" en la localidad, Giovanni Bonfiglio, consigna como fecha de creación "el 4 de noviembre de 1931, aniversario de la victoria italiana en la Primera Guerra Mundial [...] la fusión fue promovida por la embajada italiana de Lima, que envió a un representante hasta en dos ocasiones diferentes" (Bonfiglio, 1999). En efecto, las instituciones que se fusionaron fueron: la Sociedad de Beneficencia Italiana, La Sociedad XX de Setiembre y el Círculo Italiano.

El 8 de noviembre de 1933, el diario La Verdad publicó los discursos pronunciados en dicha ceremonia. El discurso más resaltante es el de Lorenzo Tarabotto, de donde se desprende esa visión mesiánica común en los italianos emigrados adherentes al fascismo, respecto a Benito Mussolini, donde lo califica como "[...] un iluminado astro se eleva en el firmamento político de la Patria, un hombre excepcional, superior y con una inteligencia y voluntad de acero" (La Verdad, 8 de noviembre de 1933, pág. 1), también agregó:

"Es él que forma el Partido Nacional Fascista, conduciendo a nuestra nación por el camino del progreso constante y duradero. Nuestro Duce posee la vitalidad, la tenacidad, la constancia de Julio César. Él se obstina perseverantemente en la verdad y obtiene por premio la grandeza de Víctor Hugo, dice: que "los tenaces, son sublimes" (La Verdad, 8 de noviembre de1933, pág.1). 
En esa oportunidad resalta la labor de Mussolini, en la reconstrucción de las estructuras materiales y espirituales de Italia como "la obra trascendental del Fascismo", y que los fines de dicho gobierno "interesan a la generalidad de los hombres porque tiende a su bienestar y comunión y sobre todo lo que da vida perdurable a este régimen en la fuerza incontenible de un amor al prójimo" (La Verdad, 8 de noviembre de 1933, pág. 1). Finaliza agregando que "la inmensa mole de obras que ha realizado el Gobierno de la Italia Fascista en toda la península necesitaría para detallarlo muchos volúmenes" (La Verdad, 8 de noviembre de1933, pág. 1).

$Y$ sobre el corporativismo, como aquel sistema de organización del Estado Fascista y que comprendía todos los aspectos de la vida política italiana, que en el campo económico -según Mussolini- pretendía superar las diferencias entre el capital y el trabajo, rompiendo con la supremacía de uno sobre el otro, conciliándolas en armonía con los intereses de la Nación, que buscaba ser una tercera vía entre el socialismo y el liberalismo (Mussolini, 1937), Lorenzo Tarabotto señala:

"Nuestro Régimen de Gobierno ha creado el Estado Corporativo Fascista, que es sin duda alguna, una de las obras más trascendentales para el porvenir de Italia y del mundo, él ha iniciado la paz social y conciliada la colaboración entre el capital y el trabajo...". (La Verdad, 8 de noviembre de 1933 , pág. 1)

\section{VISIÓN Y D IFUSIÓN DEL FASCISMO: DIARIO LA VERDAD}

El diario local La Verdad, otrora elemento propagandístico del partido Unión Revolucionaria, luego de la muer- te del caudillo el general Luis M. Sánchez Cerro, ya no publicita las constantes actividades del comité urrista local; inclusive, el diario se declara apartado de la labor política que realizaba, pues "no quiere resucitar, épocas del periodismo tacneño poco gratas del recuerdo" (La Verdad, 12 de julio de 1933, pág. 1), también desaparecen los constantes ataques al aprismo, pero por otro lado crece la "influencia italiana" y la propaganda explícitamente fascista sobre el régimen de Mussolini.

Es así que el 17 de junio se publica un artículo escrito por el dirigente del Fascio Italiano en Lima (Toto Giurato) sobre la realidad italiana bajo el régimen de Mussolini, denominado "Fascismo, Realidad Italiana". En dicho artículo Toto Giurato señala como génesis del fascismo, una situación de "profunda desilusión del pueblo italiano victorioso y traicionado en la paz por aquellos que del esfuerzo de Italia [...] fuertemente se beneficiaron" (La Verdad, 12 de julio de 1933, pág. 1) siendo ésta entonces, una obra de "dignidad nacional", argumento similar al que sostenían los adherentes al desaparecido Gral. Luis Miguel Sánchez Cerro (La Verdad, 24 de agosto de 1932, pág. 3), lo cual justifica la difusión de las experiencias "nacionalistas" del extranjero, por los medios de comunicación alineados anteriormente a este régimen, pues beneficiaria a ambos lados, por un lado a los "fascistas" de la colonia italiana, como propaganda del régimen y la "internacionalización" del fascismo, $\mathrm{y}$ a los nacionalistas (que virarían al fascismo, la "Unión Revolucionaria") la difusión de una experiencia que consideraban exitosa de un gobierno nacionalista, generando expectativas favorables en la población. Además, durante el periodo de gobierno posterior a la muerte de Luis M. Sánchez Cerro -que presidió Oscar R. Benavides- que si bien no 
manifestaba abiertamente tener simpatías con el fascismo ni realizó reformas para tener un Estado que se asemeje al de la Italia Fascista (el Estado Corporativo) y su inclinación hacia ella habría tenido el propósito de encontrar un justificante ideológico para una dictadura (Valdez, 2004), se potenciaron las relaciones diplomáticas con Italia, expresadas en la intervención de Italia en la solución del conflicto de Leticia, el fortalecimiento de los vínculos militares entre ambos países o las facilidades que dio el Gobierno para el comercio con Italia aun cuando admitió la sanción establecida por la Sociedad de Naciones en 1935 por la invasión a Etiopía (Valdez, 2004).

Toto Giurato señala además que el Partido Nacional Fascista agrupa en sus filas a todas las fuerzas sociales del país, como los sindicatos, las milicias voluntarias (ferrocarrileras, rurales, portuarias, forestales, de servicios de correo), a los legionarios en Libia, a las mujeres (por medio de los fascios femeninos) y los grupos universitarios, quienes hasta ese momento sumarían 1700000 inscritos y para quien el fascismo significaría "Doctrina, obra y hombres fundidos graníticamente, presentan a la faz del Mundo la realidad indestructible de la Nueva Italia Fascista que es escudada y unida a su Rey, a su Duce, mira con confiada certidumbre su gran porvenir" (La Verdad, 12 de julio de 1933).

También se publica semanalmente en dicho diario "El Boletín de informaciones de 'Il Littoriale'" el cual informaba sobre los principales acontecimientos ocurridos en Italia durante la semana (de índole política, económica y cultural).

Siguiendo con la realidad italiana en el régimen de Mussolini, se publica un artículo del diplomático Emilio Ortiz de Zevallos y Vidaurre, quien fuera enviado a Roma en 1930, titulado "El Valor del Fascismo", donde expone los fundamentos del fascismo, como modelo de Estado, señalando que "[...] Si la política es profesión de fe y decidida égida hacia un país más risueño, bien se puede afirmar que el régimen fascista, en sus diez años de existencia, ha demostrado su capacidad en tal sentido [...]" (La Verdad, 19 de agosto de1933, pág. 2).

Pero no deja de resaltar que como motor de tal proyecto está Benito Mussolini "como artífice de esta obra; como guía espiritual de esta conducta política, creatriz al mismo tiempo de la doctrina y del método, se levanta la figura extraordinaria de un hombre: Benito Mussolini y de aquellos grandes guías comprensivos de la historia [...]" (La Verdad, 19 de agosto de1933, pág. 2).

En un artículo titulado "Los Italianos de Tacna", se realiza una cronología de los miembros más resaltantes de esta localidad, entre los cuales se destaca un considerable número de colonos que regresaron a servir a su patria en la Primera Guerra Mundial, como Humberto Bollo, agente consular en 1932, asimismo se reconoce a Lorenzo Tarabotto -el Presidente de la "Casa de los Italianos" y Julio Cesar Raffo, quien fuera agente consular de Italia y España, nombrado Caballero de la Corona de Italia por el Gobierno de Mussolini. (La Verdad, 22 de agosto de 1933, pág. 1). Al respecto Giovanni Bonfiglio afirma que fueron veintinueve los jóvenes italianos que regresaron a Italia para luchar en la Primera Guerra Mundial, de los cuales dos cayeron en combate, quienes fueron recordados como héroes por la comunidad italiana local, esto probaría "la existencia de fuertes lazos de cohesión étnica dentro de la colonia de Tacna" (Bonfiglio, 1999).

El 10 de marzo de 1934, cuando lo regular eran noticias de Alemania e Italia, pero sin emitir juicios de valor, o amenos estos eran muy tímidos, en la 
editorial de ese día califica a ambos países y sus regímenes como arquetípicos. Respecto a Italia dirá:

"[...] Fue necesario que el Duce se impusiera la tarea por demás difícil de formar antes la conciencia popular y lo ha conseguido forjando el alma italiana en el yunque del Orden, del Trabajo, y de la Sumisión a la Ley. Por eso, la Nación Italiana marcha ahora con paso firme hacia el pináculo de la gloria" (La Verdad, 8 de noviembre de1933, pág. 2).

\section{LA "EDUCACIÓN FASCISTA" Y EL "GIARDINO D'INFANZIA ITALIANO" DETACNA}

La educación ocupó un lugar importante en el régimen de Mussolini, pues partiendo de la cosmovisión fascista "hacer un nuevo hombre requería invertir en un reforma general de la educación que incidiera en los valores fascistas de valentía, patriotismo y sacrificio para la comunidad nacional" (Bolinaga Irausegui, 2010).

$\mathrm{Al}$ insertarse los Fasci all'estero dentro de la administración del Ministerio de Relaciones Exteriores (superando el dualismo que existía anteriormente), como señala Eduardo Gonzales Calleja, la entidad incrementa sus funciones, así como los órganos dependientes de ella, por ejemplo "Al secretario general le fue conferido el grado de cónsul general de primera clase y la dirección de las escuelas italianas en el extranjero a partir de noviembre de 1928" (Gonzales Calleja, 1994).

En 1929, se fusiona la Direzione Generale delle Scuole Italiane all' Estero con la Direzione Generale degli Italiani all'Estero convirtiéndose en la Direzione Generale per gli Italiani all'Estero e Scuole, "cuyas competencias se ampliaron a los fascios, a las cuestiones migratorias y laborales y a las escuelas en el extranjero (Gonzales Calleja, 1994).

En el caso del Perú, el fascio de Lima tenía presencia en los colegios Antonio Raimondi y Regina Margherita del Callao (Lopez Soria, 1981). En Tacna, inspirada en las directivas del gobierno fascista, y por impulso de los miembros de la Casa Degli Italiani, quienes como señalamos anteriormente, eran adherentes de la obra de Mussolini y su proyecto de renovación nacional, se funda "Giardino D'Infanzia Italiano", hoy colegio Santa Ana, que abre sus puertas en 1932, siendo la única institución de este tipo en el interior del país (Bonfiglio, 1999).

Con relación a dicha institución, haciendo una comparación con otras instituciones educativas extranjeras que buscan convertir a los ciudadanos de un país en "extranjeros", se publica en el diario La Verdad un artículo titulado "El Asilo de infancia italiano de Tacna", donde se afirma que es política del Gobierno Fascista que las instituciones italianas eduquen el amor al país que los cobija, labor que cumplían las instituciones educativas italianas en todo el país.

"[...] Para confirmar y acrecentar este amor en el corazón de los alumnos en el Asilo de Infancia de Tacna, como en el Colegio Italiano de Lima, se celebran diariamente, todas las efemérides históricas del calendario civil oportunamente, después de la plegaria se eleva a la Patria el Canto Solemne del Himno Nacional y siempre cuando se presente la ocasión propicia, los enseñantes italianos, reúnen delante de la bandera del país que galantemente los hospeda, a sus alumnos, y con severo ritual le rinden el culto de amor, de devoción, gratitud y de "respeto" a las leyes y autoridades del país, que 
el mismo Jefe de Gobierno Fascista recomienda en forma especial a todos los italianos que residen en el extranjero; de respeto sobre todo, porque solo respetando, se tiene derecho a ser respetado [...]" (La Verdad, 15 de agosto de 1933, pág.3).

Si tomamos en cuenta que esto surge luego del reordenamiento de las instituciones italianas en el extranjero, que a partir de 1928, -como tratamos anteriormente- se emprende una política exterior "moderada", para lo cual se crearon las "Casas de los Italianos" (en contraparte a la propaganda agresiva de los primeros fasci all' estero), es comprensible este giro en la táctica propagandística. Es decir, esta concepción, que podríamos denominar "ética" de la educación italiana con relación a los Estados huéspedes, el gobierno de Mussolini buscaba la propagación de la doctrina fascista, ya no precisamente por medio de la latinidad, sino por medio de su "esencia" que es el nacionalismo, del cual podría germinar un "fascismo" acorde a las realidades nacionales, solo de este modo se puede explicar el surgimiento de partidos que adoptaron la ética y estética del fascismo, como fue la "Unión Revolucionaria" al mando de Luis A. Flores (Lopez Soria, 1981; Molinari, 2009).

\section{CONCLUSIONES}

El caso de la Colonia Italiana de Tacna, dentro del periodo estudiado, refleja un carácter sui generis, respecto a las otras colonias del interior del país -solo equiparable a la de la capital- por la existencia y funcionamiento de sus principales instituciones (fuerte carácter asociativo y de cohesión étnica).

Con relación al fascismo y el con- trol que ejercía sobre las colonias por medio de los fasci all'estero y luego por instituciones más moderadas, como la "Casa degli Italiani", podemos plantear que la colonia italiana de Tacna jugó un rol importante en la consecución de fines políticos del régimen de Mussolini en el extranjero (control ideológico, seguridad y propaganda), en cuanto fue la única ciudad fuera de Lima que contó de manera estable con un apéndice del PNF: el "Fascio de Tacna", llamado oficialmente "Giovanni Berta", fundado en 1922

Luego de las reformas emprendidas por el gobierno italiano en 1928, respecto a la representación y organizaciones en el extranjero, que mostrara un rostro moderado de la Italia fascista, es que se crea la "Casa degli Italiani". En Tacna, al aglutinar todas las actividades de la vida del inmigrante italiano (las cuales eran exclusivas en cuanto se buscaba evitar la desnacionalización), sirvió de medio difusor de las obras de Mussolini en Italia, $y$ al no presentarse como apéndice del PNF, ni apelando a la retórica del squadrista, generó una relación de paridad entre patriotismo (o nacionalismo) y fascismo.

\section{REFERENCIAS BIBLIOGRÁFICAS}

Bolinaga Irausegui, I. (2010). Breve Historia dle Fascismo. Madrid: Ediciones Nowtilus S.L.

Bonfiglio, G. (1999). Gli italianni nella societá peruviana: una visione stori$\mathrm{ca}$. Torino: Edizioni della Fondazione Giovanni Agnelli.

Choque, E. (1988). La Burguesia Comercial en Tacna. Tacna: Pacoyunque Editories.

Diaz, A. y Pizarro, E. (2004). Algunos antecedentes de la presencia italiana en la ciudad de Tacna 18851929". Rev. Historia Universidad 
San Agustin, 171-188.

Dominguez, R. (2012). Dos instrumentos en la propaganda exterior del fascismo: emigración y cultura. Hispania Nova. Revista de Historia Contemporánea. Núm. 10 http:/ / hispanianova.rediris.es.

Ferreira de Cassone, F. (2008). El APRA y su proyección americana a través de la revista Claridad (1926-1941). Exclusivo para el Taller Orrego.

Gonzales Calleja, E. (1994). La derecha latinoamericana en busca de un modelo fascista: la limitada influencia del falangismo en el Perú (1 936-1945). Revista Complutense de Historia de América, núm. 20., 229-255.

Grillo, M. V. (2006). Creer en Mussolini, La proyección exterior del fascismo italiano (Argentina, 19301939). Revista Ayer No 62 Más allá de la historia social, 231-255.

Lopez Soria, J. I. (1981). El Pensamiento Fascista (1930-1945). Lima: Mosca Azul Editores.

Molinari, T. (2009). El fascismo en el Perú: La Unión Revolucionaria 1931-1936.
Lima: Fondo Editorial de la Facultad de Ciencias Sociale- UNMSM.

Mussolini, B. (1937), La Doctrina del Fascismo. Madrid: Editorial Libreria San Martin.

Pane, C. (2012). Le Case d' Italia in Francia, Organizzazione, attivitá e rappresentazione del fascimo all'estero. Rivista Memoriae Ricerca No 41, 161-180.

Panty, O. (2001). Función orientadora en la Prensa Escrita. Tacna: Educa.

Savarino, F. (2010). Fascismo en América Latina: La perspectiva italiana (1922-1943). Diálogos - Revista do Departamento de Historia e do Programa de Pós-Graduação em História, vol. 14, núm., 39-81.

Valdez, F. D. (2004). Las Relaciones entre Perú e Italia (1821-2002). Serie: Política Exterior Peruana. Lima: Fondo Editorial de la Pontificia Universidad Católica del Perú.

Vivarelli, R. (2012). Storia delle origini del fascismo, Vol. III. Il Mulino.

Fuentes Hemerográficas del Archivo Regional de Tacna:

Diario La Nación (1931), Tacna.

Diario La Verdad (1932-1934), Tacna. 